\title{
Effects of Noise on Rabbit's Blood
}

\section{Khitam Elwasife ${ }^{1, \text { *, Ismail Abdel Aziz }}{ }^{2}$, Mhammad Shabat ${ }^{1}$, Osama Shahwan ${ }^{3}$, Al Monther El Hamidi ${ }^{2}$}

${ }^{1}$ Islamic university of Gaza, Department of Physics, Faculty of science, Gaza strip, Palestinian Authority

${ }^{2}$ Islamic university of Gaza, Department of Biology, Faculty of science, Gaza strip, Palestinian Authority

${ }^{3}$ El-Manar Lab, Khan Yunis, Gaza strip, Palestinian Authority

\section{Email address:}

kelwasife@iugaza.edu.ps (K. Elwasife)

\section{To cite this article:}

Khitam Elwasife, Ismail Abdel Aziz, Mhammad Shabat, Osama Shahwan, Al Monther El Hamidi. Effects of Noise on Rabbit's Blood. International Journal of Economics, Finance and Management Sciences. Vol. 3, No. 2, 2015, pp. 10-13. doi: 10.11648/j.ejb.20150302.11

\begin{abstract}
Experiments are described in which domestic rabbits were deliberately subjected to a daily 3-4 hours noise regime $(65 \mathrm{~dB})$ for 18, 28, 40 and 50 days, to determine its effects on the blood. Noise exposure to rabbits caused a general increase in its biochemical parameters such as urea, uric acid, creatinine, cholesterol, and triglycerides, while glucose level decreased significantly. Our results indicate a general decrease of total protein, albumin and globulin levels. The results indicated that noise exposure at split dose could be harmful. It found that recovery period were able to alleviate some of those harmful changes.
\end{abstract}

Keywords: Noise, Recovery Period, Blood Indices Domestic Rabbits

\section{Introduction}

Noise, defined as disturbing and unwanted sound, is perceived as an environmental stressor and nuisance. Noise is a pervasive aspect of many modern communities, work environments. Its damaging effects particularly the productions of free radicals are not limited to the auditory organ. The response to noise may depend on characteristics of the sound, including intensity, frequency, and complexity of sound, duration and the meaning of the noise [1]. Exposure to noise causes many health problems such as hearing loss, sleep disturbance, and impairs performance as well as effecting cognitive performance. It also increases aggression and reduce the processing of social cues seen as irrelevant to task performance as well as leading to coronary heart disease, hypertension, higher blood pressure, increased mortality risk, serious psychological effects, headache, anxiety, and nausea [2-4]. Reha et al have been investigate the effect of noise on oxidative stress parameters in rat [5]. Several studies have shown that noise in animal care facilities can reach as high as $90-100 \mathrm{~dB}$ [6]. Such levels of noise can induce physiological and behavioral responses in laboratory rodents such as increased plasma corticosterone levels, reduction in body weight, decrease in gastric secretion, changes in immune response and tumor resistance, and a decrease in reproductive function. Behavioral responses include increases in total activity, grooming themselves and their cage-mates, and rearing onto their hind legs [7-12]. These changes are similar to those seen in rodents exposed to other stressful situations $[13,14]$. In spite of the evidence that noise levels in animal facilities are often high enough to produce uncontrolled physiological and psychological responses, the acoustic levels continue to be not as monitored as other environmental factors (lighting, temperature, humidity, etc). Cynthia Hohmann et al have been evaluated the association between chronic noise exposure during pregnancy and birth outcomes and the health of foetuses and infants and the association between chronic noise exposure and stress indicators, cardiovas-cular risk factors and immune-mediated diseases such as asthmaand allergy in children[15]. The effect of noise exposure on blood pressure and heart rate of steel industry workers have been investigated by Zahra Zamanian [16]. Materials and methods in the study were, 50 workers were selected from a steel company in Fars province, Iran, and exposed to 85, 95, and $105 \mathrm{~dB}$ noise levels for 5 minutes. The participants' blood pressure and heart rate were measured using Beurer BC16 pulse meter both before and after the exposure. The Results has been showed no significant difference in blood pressure and heart rate before and after the exposure. However, the workers' systolic blood pressure had increased compared to before the exposure; of course, the difference was not statistically significant (0.05). Besides, although the subjects' heart rate had reduced in comparison to before the exposure, 
the difference was not statistically significant $(>0.05)$. No significant change was observed in blood pressure and heart rate after acute exposure to 85,95 , and $105 \mathrm{~dB}$ noise levels. Thus, the present study aims to investigate the hematological and biomedical effects of noise in adult rabbits.

\section{Materials and Methods}

The study was conducted in 36 male rabbits (w 1000 $1200 \mathrm{~g}$ ). During the course of the study the animals were housed in pairs in the animal house with food and water and kept under standard environmental conditions for light (12: $12 \mathrm{~h}$ light: dark cycle) temperature $\left(27^{\circ} \mathrm{C}\right)$ and noise levels (60-70 dB) On the days of the test the rabbits were brought to the laboratory. The experiment was conducted at

Gaza strip laboratory. The use of these experimental animals was approved by Veterinary Service of the Municipality of Gaza-Palestine

The animals divided into six groups

The first group consists of ten rabbits and it acts as control

The second, third, fourth and fifth group were exposured to the noise for $(18,28,40$ and50 )days respectively, while the sixth group are exposed to the noise for 50 days and left untreated for one month to recovery. The animals were exposed to noise product from generator with $1 \mathrm{KW}$ and dimension of $1200 \mathrm{mmx} 1100 \mathrm{mmx} 1300 \mathrm{~mm}$. They exposure for 3-4 hour in each day. At the end of the experiment, animals from both control and experimental groups were decapitated. After wards, the blood samples were collected between 6-7 $\mathrm{mL}$ from each rabbit depending on the rabbit body weight. For the hematological tests, approximately 2-3 $\mathrm{mL}$ of blood sample was received at a tube containing dipotassium ethylene diaminetetra acetate (EDTA). In addition, about $2-3 \mathrm{~mL}$ of blood was collected into a centrifuge tube without any anticoagulant for the biochemical tests [17]. Blood samples were collected in $10 \mathrm{ml}$ plain tubes for serum preparation. Clear serum samples were separated by centrifugation at 3000 r.p.m for $20 \mathrm{~min}$. Serum glucose, triglycerides and total cholesterol were determined using the method described by Trinder(18), Fossati and Prencipe(19) and Allain etal(20). Serum total protein was determined according to the Biuret reaction as described by Bellossi et al. [21]. The kits were purchased from Biotech laboratories, U.K. Serum albumin was determined using Randox reagent kits and following their instruction manual according to the method of Doumas et al. [22]. The concentrations of globulin were calculated by the following equation: Concentration of globulins $(\mathrm{gm} / \mathrm{dl})=$ Total protein-Albumin [23-25].

\subsection{Hematological Parameters}

Determination of hematological parameters was carried out using an 18 automated parameter hematology analyzer. ABX Micros 60 from Horiba ABX. France.

\subsection{Data Analysis}

Data were computer analyzed using SPSS version 11.0 for windows (Statistical Package for the Social Sciences lnc. Chicago, Illinois, USA). Means were compared by independent-samples test, $\mathrm{p}<0.05$ was considered as significant. Percentage change was also calculated.

\section{Results}

Serum glucose, triglycerides and total cholesterol, mean values of rabbits affected by noise exposure with/ without recovery are summarized in table (1). The data revealed that noise exposure for 50 days decreased serum glucose level by $-36.73 \%$ compared the control level. But after in recovery group decrement of serum glucose to $-5.39 \%$, compared to the control level, on the other hand triglycerides increased gradually and non-significantly from the first ten days treatment till 50 days $(\mathrm{p}<0.05)$. On the other hand, mean values of serum cholesterol was significantly increased by $13.5 \%$ in noise treated rabbit for 50 days compared to the control. in general, noise exposure increased urea, uric acid, and creatinine compared to control level. the noise exposure was more pronounced on urea. However in recovery period were able to lowered the elevated values as illustrated in table (2). Total protein values were decrease exhibiting percentage decreased of 5.39\% and $11.03 \%$ in 40 and 50 days respectively compared to control levels (table 3 ). Albumin concentration rabbit's blood serum under the influence of noise for $28,40,50$ days decreased by $3.5 \%, 7.07 \%$ and $16.67 \%$ respectively. on the other and results in table (3) indicated in significant decrease in globulin concentration after noise exposure treatment for 18,28,40 and 50 days.

Table (1). Glucose, Cholesterol, Triglycerides, Urea, Uric acid, and creatinine in rabbits after noise exposure.

\begin{tabular}{|c|c|c|c|c|c|c|}
\hline \multirow{2}{*}{ Parameters } & \multicolumn{6}{|c|}{ Experimental Period } \\
\hline & Control N=10 & 18 days $N=6$ & 28 days $N=6$ & 40 days $N=6$ & 50 days $N=6$ & Recovery (30 days) $N=6$ \\
\hline Glucose (mg/dl) & & $80.21 \pm 0.39$ & $69.36 \pm 0.50$ & $62.8 \pm 0.41$ & $60.30 \pm 0.32$ & $90.16 \pm 0.36$ \\
\hline$\%$ change & $95.30 \pm 0.61$ & $15.83-$ & -27.22 & -34.10 & -36.73 & -5.39 \\
\hline$P$ value & & $\prec 0.01$ & $\prec 0.01$ & $\prec 0.01$ & $\prec 0.01$ & $0.05>$ \\
\hline Triglycerides(mg/dl) & & $115.50 \pm 0.30$ & $116.10 \pm 0.25$ & $118.80 \pm 0.31$ & $119.90 \pm 0.39$ & $110 \pm 0.26$ \\
\hline$\%$ change & $100.20 \pm 0.29$ & 15.27 & 15.87 & 18.56 & 19.66 & 10 \\
\hline$P$ value & & $\prec 0.01$ & $\prec 0.01$ & $\prec 0.01$ & $\prec 0.01$ & $\prec 0.05$ \\
\hline Colesterol(mg/dl) & & $175.0 \pm 0.36$ & $180.10 \pm 0.33$ & $189.61 \pm 0.37$ & $195.11 \pm 0.30$ & $188.0 \pm 0.31$ \\
\hline$\%$ change & $171.90 \pm 0.55$ & 1.8 & 4.77 & 10.30 & 13.5 & 9.37 \\
\hline$P$ value & & $0.05>$ & $>0.05$ & $\prec 0.05$ & $\prec 0.05$ & $0.05>$ \\
\hline
\end{tabular}

All values were expressed as mean \pm S.E; $\mathrm{P}<0.05$ significant; $\mathrm{P}<0.01$ highly significant 
Table (2). Urea, Uric acid and Creatinine in rabbits after noise exposure.

\begin{tabular}{|c|c|c|c|c|c|c|}
\hline \multirow[b]{2}{*}{ Parameters } & \multicolumn{6}{|c|}{ Experimental Period } \\
\hline & $\begin{array}{l}\text { Control } \\
\mathrm{N}=10\end{array}$ & $\begin{array}{l}18 \text { days } \\
N=6\end{array}$ & $\begin{array}{l}28 \text { days } \\
N=6\end{array}$ & $\begin{array}{l}40 \text { days } \\
N=6\end{array}$ & $\begin{array}{l}50 \text { days } \\
N=6\end{array}$ & $\begin{array}{l}\text { Recovery } \\
\text { (30 days) } N=6\end{array}$ \\
\hline Urea $(\mathrm{mg} / \mathrm{dl})$ & & $29.99 \pm 0.51$ & $30.86 \pm 0.44$ & $40.11 \pm 0.39$ & $46.67 \pm 0.45$ & $25.77 \pm 0.36$ \\
\hline$\%$ change & $25.10 \pm 0.6$ & 19.48 & 46.85 & 59.80 & 88.94 & 14.62 \\
\hline$P$ value & & $\prec 0.01$ & $\prec 0.01$ & $\prec 0.01$ & $\prec 0.01$ & $\prec 0.01$ \\
\hline Uric acid $(\mathrm{mg} / \mathrm{dl})$ & & $3.13 \pm 0.18$ & $3.89 \pm 0.19$ & $3.99 \pm 0.17$ & $4.73 \pm 0.25$ & $3.30 \pm 0.22$ \\
\hline \%change & $3.11 \pm 0.11$ & 0.64 & 5.43 & 28.30 & 52.09 & 6.11 \\
\hline$P$ value & & $\succ 0.05$ & $\succ 0.01$ & $\prec 0.01$ & $\prec 0.01$ & $\prec 0.05$ \\
\hline Creatinine $(\mathrm{mg} / \mathrm{dl})$ & & $0.86 \pm 0.08$ & $0.89 \pm 0.05$ & $1.3 \pm 0.06$ & $1.50 \pm 0.09$ & $0.83 \pm 0.03$ \\
\hline$\%$ change & $0.80 \pm 0.04$ & 7.5 & 10.47 & 62.5 & 87.5 & -33 \\
\hline P value & & $0.05 \succ$ & $\prec 0.05$ & $\prec 0.01$ & $\prec 0.01$ & $\prec 0.01$ \\
\hline
\end{tabular}

Table (3). Total protein, albumin, and globulin in rabbits after noise exposure

\begin{tabular}{lllllll}
\hline Parameters & Experimental Period & & & \\
\%change & $\begin{array}{l}\text { Control } \\
\mathbf{N = 1 0}\end{array}$ & $\begin{array}{l}\mathbf{1 8} \text { days } \\
\mathbf{N = 6}\end{array}$ & $\begin{array}{l}\mathbf{2 8} \text { days } \\
\mathbf{N = 6}\end{array}$ & $\begin{array}{l}\mathbf{4 0} \text { days } \\
\mathbf{N = 6}\end{array}$ & $\begin{array}{l}\text { P value50 days } \\
\mathbf{N}=\mathbf{6}\end{array}$ & $\begin{array}{l}\text { Recovery } \\
\mathbf{( 3 0} \text { days)N=6 }\end{array}$ \\
\hline Total protein(mg/dl) & & $7.87 \pm 0.25$ & $7.60 \pm 0.21$ & $7.55 \pm 0.23$ & $7.10 \pm 0.20$ & $7.93 \pm 0.26$ \\
\%change & $7.98 \pm 0.28$ & -1.38 & 4.76 & -5.39 & -11.03 & -0.63 \\
P value & & $0.05>$ & $-0.05>$ & $0.05>$ & $<0.05$ & $0.05>$ \\
Total Albumin(mg/dl) & & $3.91 \pm 0.11$ & $3.75 \pm 0.13$ & $3.68 \pm 0.12$ & $3.30 \pm 0.15$ & $3.93 \pm 0.17$ \\
\%change & $3.96 \pm 0.41$ & -1.26 & -5.30 & -7.07 & -16.67 & -0.76 \\
P value & & $0.05>$ & $0.05>$ & $0.05>$ & $<0.01$ & $0.05>$ \\
Total Globulin(mg/dl) & & $3.96 \pm 0.13$ & $3.85 \pm 0.11$ & $3.87 \pm 0.14$ & $3.80 \pm 0.16$ & $4.00 \pm 0.21$ \\
\%change & $4.02 \pm 0.10$ & -1.49 & -4.22 & -3.73 & -5.47 & -0.50 \\
P value & & $0.05>$ & $0.05>$ & $0.05>$ & $0.05>$ & $0.05>$ \\
\hline
\end{tabular}

All values were expressed as mean \pm S.E; $\mathrm{P}<0.05$ significant; $\mathrm{P}<0.01$ highly significant.

\section{Discussion}

Data revealed highly significant decrease in serum glucose levels in rabbits in response to noise exposure. Noise exposure may indirectly, play a specific role in carbohydrate metabolism probably due to enhancing gluconeogenesis and glucose mobilization to the blood [24]. The change observed in serum triglycerides and cholesterol content in response to treatment by noise drug; take place in the liver due to imbalance between the normal rabbits of lipid synthesis, utilization and secretion [26]. The increment in cholesterol and triglyceride content agreed with that reported by Parker [27]. The possible explanation of these observed increments may be explained on indirect action of noise on lipid metabolism or lipid peroxidation [17]. The highly significant in blood urea is the principal end product of protein catabolism an accelerated amino acid deamination for gluconeogenesis is probably an acceptable postulate to interpret the elevated level of urea. The increment in blood urea, might be also due to the destruction of RBCs during the treatment. The presence of some toxic compounds might increase blood urea and decrease plasma protein [28]. On the other hand the elevation of blood urea might suggest that animals experienced hemoconcentration due to mild dehydration [29].

Moreover, the serum uric acid levels exhibited an increase in the treated rabbits for the experimental duration. This may be due to high degradation of purines or an increase of uric acid level by inability of its excretion by urinary system [30].

The non significant decreased levels of total protein in noise exposure rabbits could be attributed to an increase in amino acids deamination. This decrease in serum total protein may be due to lowered synthesis of albumen and globulin in the liver in response to Noise exposure intake. It was reported that albumin levels are decreased in liver disease [31].

The decrease in these blood proteins of the rabbit may be due to usage of different amino acids in the production of antibodies in response to noise exposure.

\section{Conclusion}

We found that the noise exposure decreased the concentrations of serum glucose, total protein, globulin, and albumin. Consequently, we found that noise exposure at split dose could be harmful. We also found that recovery period were able to alleviate some of those harmful changes.

\section{References}

[1] C. Abbate, G. Concetto , M. Fortunato," Influence of environmental factors on the evolution of industrial noiseinduced hearing loss", Environ Monit Assess, 2005,vol.107,pp. 351-61

[2] Associated with ultrastructural alterations in rat myocardium after loud noise exposure". Environ Health Perspect, 2003, vol.111, pp. 467-71.

[3] R, Ravindran, R. Devi, J. Samson, M. Senthilvelan," Noisestress-induced brain neurotransmitter changes and the effect of ocimum sanctum (Linn) treatment in albino rats", J Pharmacol Sci, 2005, vol.98, pp. 354-60. 
[4] S. Stansfeld, M. Matheson," Noise pollution: non-auditory effects on health. Br Med Bull, 2003, vol.68, pp. 243-57.

[5] R. Demirel, H. Mollaoğlu, H. Yeşilyurt, K. Üçok, A. Ayçiçek3, M. Akkaya, A. Genç, R. Uygur4, M. Doğan," Noise Induces Oxidative Stress in Rat",Eur J Gen Med, 2009,vol.6,pp. 20-24.

[6] L. Crista, "Noise in the Animal Shelter Environment: Building Design and the Effects of Daily Noise Exposure", Journal Of Applied Animal Welfare Science, 2001, vol.9, pp.1-5.

[7] A. Baldwin, R, Primeau, \& W. Johnson," Effect of noise on the morphology of the intestinal mucosa in laboratory rats. Contemporary Topics of Laboratory Animal Science, 2006, vol. 45 pp. $74-82$.

[8] A. Baldwin,I. Bell ," Effect of noise on microvascular integrity in laboratory rats", Journal of American Assoc. for Laboratory Animal Science,2007,vol. 46 pp. 58-65.

[9] A. Burwell, A, Baldwin ," Do audible and ultrasonic sounds of intensities common in animal facilities affect the autonomic nervous system of rodents, Journal of Applied Animal Welfare Science,2006, vol.9,No. 3, pp.179-199.

[10] G. Clough," Environmental effects of animals used in biomedical research. Biological Reviews of the Cambridge Philosophical Society, 2005, vol. 57pp. 487-523.

[11] K. Kramer, S. van, H. Voss, A. Grimbergen" Use of telemetry to record electrocardiogram and heart rate in freely moving mice. Journal of Pharmacological Toxicological Methods, 1993, vol. 30, pp. 209-215.

[12] K. Kramer, H. Voss, J. Grimbergen, P. Mills, D. Huetteman, ," Telemetric monitoring of blood pressure in freely moving mice",A preliminary study. Laboratory Animals, 2000, vol.34, pp. 272-280.

[13] J. Sharp, T. Azar, D. Lawson," Does cage size affect heart rate and blood pressure of male rats at rest or after procedures that induce stress-like responses", Contemporary Topics of Laboratory Animal Science, 2003,vol.42,pp. 8-12

[14] J. Sharp, T. Zammit, T. Azar, "Stress-like responses to common procedures in male rats housed alone or with other rats",ContemporaryTopics of Laboratory Animal Science, 2002,vol.41, pp. 8-14.

[15] H. Cynthia, L. Grabenhenricha, Y. Kluizenaarb, C. Tischerc J. Heinrichc, Ch. Chenc, C. Thijsd, M. Nieuwenhuijsene,", a Health effects of chronic noise exposure in pregnancy and childhood:mA systematic review initiated by ENRIECO", International Journal of Hygiene and Environmental Health, 2013, vol4. pp. 217-229

[16] Z. Zamanian, R. Rostami,J. Hasanzadeh, and H. Hashemi ,"Investigation of the Effect of Occupational Noise Exposure on Blood Pressure and Heart Rate of Steel Industry Workers", Journal of Environmental and Public Health,2013, vol10, pp. 3-6

[17] I. Abdel Aziz, H. El-Khozondar, M. Shabat, Kh. Elwasife, A. Osman ,"Effect Of Electromagnetic Field On Body Weight And Blood Indices In Albino Rats And The Therapeutic
Action Of Vitamin C Or E, Romanian", J. Biophys., 2010, Vol 20, No. 3, pp. . 235-244.

[18] G. Walid, I. Janelle ," Homogeneous Trinder-Coupled Assay for The Determination of Glucose-6-Phosphatase Activity in Tissue Extracts, Clinical Biochemistry,1992, vol. 25, pp. 109114.

[19] P. Fossatti, L. Prencipe, G. Berti, "Use Of 3,5-Dichloro-2Hydroxyl-Benzenesulfonic Acid/4- Aminophensone Chromogenic System in Direct Enzymic Assay of Uric Acid in Serum And Urine", Clin. Chem, 1980, vol.26, pp. 227-31.

[20] C. Allain, L. Poon, C. Chan," Enzymatic Determination of Total Serum Cholesterol", Clinical Chemistry.1974, vol. 20, pp.470-475.

[21] A. Bellossi," No-effect of a Static Uniform Magnetic Field on Mouse, Trypanosomiasis. Radiation and Environmental Biophysics, 1983, vol. 22, pp. 311-313.

[22] B. Doumas, L. Hause, D. Simuncak, ," Differences Between Values for Plasma and Serum in Tests Performed in The Ektachem 700 XR Analyzer, and Evaluation of Plasma Separator Tubes (PST)", Clinical Chemistry, 1989,Vol. 35, no.1, pp: 151-153.

[23] Kh. Elwasife,H. El-Khozondar,M. Shabat, I. Abdel Aziz, A. Mohamed-Osman," Therapeutic action of Vitamin C or E on Serum Biochemical Parameters in Albino Rats exposed to Electromagnetic Field "A Preliminary Study" The Islamic University Journal (Series of Natural Studies and Engineering) 2010, vol.18, pp. $11-22$.

[24] G. Glaser, J. Mager, "Biochemical studies on the mechanism of liver poisons. II. Induction of fatty liver. Biochem . Biophys. Acta 1972, pp.261-500.

[25] O. Bessey, H. MK, "Dietary deprivation of riboflavin and blood riboflavin levels in man",.J . Nutr, 1956, vol,. 58,pp. 367-83

[26] P. Fossatti, L. Prencipe,G. Berti,, "Use Of 3,5-Dichloro-2Hydroxyl-Benzenesulfonic Acid/4- Aminophensone Chromogenic System in Direct Enzymic Assay of Uric Acid in Serum And Urine, Clin. Chem. 1980, vol.26, pp.227-31.

[27] O. Parker, V. Piccirillo, S. Kurtz," Six month synthetic feeding study of Fenvalerate in dogs, Fundam. Appl. Toxicol, 1984, vol. 4 , pp. $577-586$.

[28] H. Varely," Practical clinical Biochemistry". Fourth edition. 1976 .

[29] M. Debra, R. Manzell R.," Kidney disease in diabetes. http:/ diabetes.about.com/od/preventing complications/p/kidney disease.htm

[30] P. Wolf, D. Williams, T. Tsudaka," Methods and Techniques in Clinical Chemistry", Wiley-lnterscience, Division of John Wiley \& Sons, Inc., New York, 1972, pp. 87-91.

[31] B. Kula, "The Electric Field Effect on the Living Organism",Part II. Alanine and Asparagines Amino Transference in Guinea Pig Liver Subcellular Fractions, Medycyna pracy. 1988, vol. 39, pp. 7-13. 